\title{
Making SENS: exploring the antecedents and impact of store environmental stewardship climate
}

\author{
Niek Hensen ${ }^{1}$ • Debbie I. Keeling ${ }^{2} \cdot$ Ko de Ruyter $^{1} \cdot$ Martin Wetzels $^{1} \cdot$ Ad de Jong $^{3}$
}

Received: 28 June 2014 / Accepted: 22 April 2015 / Published online: 16 June 2015

(C) The Author(s) 2015. This article is published with open access at Springerlink.com

\begin{abstract}
Retailers increasingly recognize that environmental responsibility is a strategic imperative. However, little research has investigated or identified the factors that facilitate the successful implementation of environmentally responsible strategies across a network of customer-facing sales units (stores). We propose that a store manager's ability to lead by example facilitates this process by fostering a supportive climate for store environmental stewardship (SENS-climate). By examining the influence of store managers' actions on sales associates' perceptions of the SENS-climate, as well as the subsequent impact on their performance - measured by margins, as well as sales of green and regular products - this study demonstrates that store managers can foster a SENS-climate
\end{abstract}

Electronic supplementary material The online version of this article (doi:10.1007/s11747-015-0446-5) contains supplementary material, which is available to authorized users.

Niek Hensen

n.hensen@maastrichtuniversity.nl

Debbie I. Keeling

D.I.Keeling@lboro.ac.uk

Ko de Ruyter

k.deruyter@maastrichtuniversity.nl

Martin Wetzels

m.wetzels@maastrichtuniversity.nl

Ad de Jong

a.de-jong@aston.ac.uk

1 Department of Marketing \& Supply Chain Management, Maastricht University School of Business and Economics, Tongersestraat 53, 6211 LM Maastricht, P.O. Box 616, 6200

MD Maastricht, The Netherlands

2 School of Business and Economics, Loughborough University, Ashby Road, Loughborough LE11 3TU, UK

3 Aston Business School Marketing Group, Aston University, Aston Triangle, Birmingham B4 7ET, UK by articulating their prioritization of environmental responsibility in their operational decisions. These positive effects are sustained by relational factors, such as the moderating effect of the store manager-sales associate dyadic tenure. In contrast, when store managers display high variability in their environmental orientation, it hinders the development of SENS-climate perceptions among sales associates. If sales associates perceive an enabling SENS-climate, they achieve higher margins and more green but fewer regular sales.

Keywords Environmental stewardship · Responsibility · Articulation · Sustainability · Store climate · Green products

Environmentally responsible business practices are a strategic imperative, driven by contemporary demands from customers, investors, and regulatory bodies (Leonidou et al. 2013). "Talking green," as exemplified by the lip service paid in annual sustainability reports, no longer seems sufficient. Companies must substantiate their eco-friendly pledges by embedding environmental responsibility in their day-to-day operations and interactions with customers (Porter and Kramer 2006). This seems particularly pertinent for retailers, as environmental impacts mainly reside in the usage phase of the products that they sell (Prindle 2010). Household appliances, for example, account for most consumer energy use (Mills and Schleich 2010), and altering this usage is a main target of global environmental campaigns (e.g., WWF 2014). Thus appliance manufacturers, such as Whirlpool, Phillips, and Electrolux, and the retailers that sell these appliances, including Walmart, Best Buy, Sears, and Home Depot, acknowledge that developing environmentally friendly (green) products holds the promise of long-term competitive advantage, and they offer increasingly wide ranges of green products and services, such as appliance recycling (Brady et al. 2010; Castle 2011). 
Industry leaders recognize that consumers hold manufacturers and retailers as primarily responsible for the environmental impact of appliances, in both production and recycling, yet consumers may lack awareness that their product usage accounts for around $75 \%$ of this impact (Electrolux 2013). Many consumers' household appliance choices remain based primarily on price and function, with energy efficiency in third place (Electrolux 2013; Euromonitor International 2010b). That is, consumers' expressed desires to buy green often are not realized in practice (Karakaya et al. 2014). Despite the substantial reductions in energy use and related usage costs they promise, $\mathrm{A}++$ labeled refrigerators constitute only $3 \%$ of refrigerator sales in their fifth year on European markets (Nipkow et al. 2012). Most newly launched green appliances also incur high price premiums, limiting consumer interest to small, more affluent, environmentally conscious segments (Castle 2011; Olson 2013). Successful green products often come about only due to strict government policies that limit consumer choice or product-tax reduction incentives that compensate for their premium prices (Griskevicius et al. 2010; OECD 2008). Even when green products are classed as eco-innovations (Hofstra and Huisingh 2014), their innovativeness is not enough to boost sales, because consumers find it difficult to understand their value (Wu and $\mathrm{Chen} 2014$ ). Thus household appliance manufacturers and retailers face the challenge of educating consumers about "why to buy" green products (Castle 2011; Electrolux 2013). There is considerable agreement that it is the retailer, with their proximity to and understanding of the consumer, who likely plays a pivotal role in nudging consumers to buy green (Girod et al. 2014; Gleim et al. 2013). At the point of purchase, green marketing strategies can be realized through face-to-face communications with consumers, bridging the gap between intention and behavior (Bishop and Barber 2015; Thongplew et al. 2014; Wu and Chen 2014), but research is needed to identify how retailers can exploit these opportunities to drive green sales (Gleim et al. 2013).

Ideally, there would be convergence between retailers' willingness to sell and consumers' demand for more green goods. Instead, organizations struggle to align their environmental responsibility with optimal firm performance - an area of active debate (Lee et al. 2014). Most retailers organize their central purchasing along economies of scale and scope, but store managers have decision authority to prioritize the sales of regular or green goods and incentivize sales associates accordingly. Diversity in a product portfolio then allows for variance in interstore performance, in terms of addressing corporate level targets. Furthermore, the ambidextrous nature of achieving environmental sustainability is rarely reflected in performance parameters. Operational sales units still must meet regular sales quotas, and the impetus to sell green products is simply added on to, rather than integrated with, such parameters. Sales associates have difficulty prioritizing their sales targets and environmental goals, which leads them to seek guidance from their work unit and its collective appraisal of priorities and the kinds of behaviors likely to be rewarded (Zohar and Luria 2004). Employees often seek a sense of "the way we do things around here" by observing their operational manager's decisions and actions, rather than formal policies (Yaffe and Kark 2011). However, we know relatively little about how store managers guide sales associates in striking such a balance (Lai et al. 2010).

In response, we focus on work unit climate. Climate, as a collective sensemaking process, is linked inextricably to a specific strategic focus (Schneider et al. 2000). Organizations should engineer their climates to manage the fit between the generation (i.e., strategy) and generalization (i.e., operationalization) of ideas. Recent stewardship theory recognizes that environmental responsibility is an operational balancing act (de Ruyter et al. 2009). In turn, we argue that environmental stewardship may be the focal point for the work unit climate, providing a common reference framework for aiding decision making within sales units, such that it helps translate organization-wide guiding environmental principles for the customer-facing network of sales units, subject to local store-level interpretation. Store managers translate principles into store priorities, which then guide sales associates in their daily interactions with customers. Support for this type of conceptual merging comes from de Ruyter et al. (2009) and Hernandez (2012), who stress the importance of collective processes and the role of managers in developing shared perceptions that steer employees toward behaviors that reflect a sense of responsibility for the welfare of multiple stakeholders.

An important contribution of this paper is, therefore, to introduce Store Environmental Stewardship Climate (SENSclimate). This social-cognitive construct delineates the realization of organizational environmental principles, manifested as operational decisions and interactions with customers. The prioritization of an environmental focus derives from the procedural patterns of the proximal work unit, in the form of interpretations of the formal guidelines and policies on the environment. We posit that SENS-climate thus should become manifest in three distinct but interlinked collective beliefs and behaviors. These are based on perceived group norms that facilitate green sales and reflect the interests of three key stakeholders: the immediate work unit, the company, and the customer. That is, we specify three SENS-climate dimensions:

(1) A sense of shared responsibility toward the environment, reflected in daily activities and actions focused on meeting personal and store-level performance targets.

(2) Initiatives to improve the ways the store contributes to reducing the company's environmental impact.

(3) Efforts to promote environmentally responsible choices by a wider range of customers while also meeting their demands. 
Beyond this contribution, we also define how a SENSclimate can be shaped through operational leaders' influence. Previous research has mainly studied relationship aspects to describe how leaders foster stewardship (de Ruyter et al. 2009; Hernandez 2008). We argue instead that a leader's taskoriented actions effectively articulate strategic choices and prioritization among available options, thus providing direction for the development of a work climate that fosters environmental responsibility. In addition, we account for how relationship-oriented behavior aids the sustainable creation of a SENS-climate, because both articulation and sustainability are critical to a collective interpretation of the environmental marketing doctrine in an operational (retail) context (Challagalla et al. 2014). Thus consistency in green sales can be promoted; this consistency then reinforces the credibility of the organization as green among consumers (Gleim et al. 2013).

As a third contribution, we examine the impact of the perceived SENS-climate on three performance parameters: margins, regular product sales, and green product sales. We propose that the development of a SENS-climate should increase sales of environmentally friendly products, which are often priced at a premium. Previous research indicates that pursuing environmental strategies can result in financial performance sacrifices at an aggregate level (e.g., de Ruyter et al. 2009). However, we argue that focusing on aggregate-level performance might not provide the full picture. By examining outcomes at a disaggregate level instead (i.e., differentiating sales of green versus regular products by individual sales associates), we disentangle the impact of a SENS-climate across green and regular product sales, which helps clarify the decisions made within the sales unit and their fit with the overall guiding principles of the environmental marketing doctrine. In particular, this approach enhances our understanding of the direct impact that retailers can exert on consumers' adoption of innovative green products.

In the next section, we introduce and develop the SENSclimate concept, merging literature on environmental responsibility, stewardship, and climate. Through a marketing doctrine lens, we then develop hypotheses of the likely antecedents and impacts of a SENS-climate. With empirical data from store managers, sales associates, and company records, we examine the hypothesized effects of store managers' decisions on employees' SENS-climate perceptions and then on performance in terms of reported margins and sales of green and regular products. Finally, we discuss the implications of our findings.

\section{The SENS-climate concept}

Environmental responsibility refers to "practices that benefit the environment (or mitigate the adverse impact of business on the environment) that go beyond those that companies are legally obliged to carry out" (Gunningham 2009, p. 215). The possible range of practices is diverse, including modifying production processes, offering recycling services, and providing consumer education. An organization's environmental responsibility is very locally oriented to the context in which that organization operates. Each organization also has its own strategy, structure, and stakeholder pressures that direct its approach to environmental responsibility, which it adopts in conjunction with its goals to maintain or improve organizational performance (Lee et al. 2014). In turn, environmental responsibility demands a fundamental shift in the mindset of customer-facing frontline employees. Their role is not determined by passive obligation but by proactivity, and they must integrate shorter term performance goals with longer term environmental goals. They must want to act, know how to act, and know how to achieve goals during interactions with customers.

For companies to adapt to contemporary demands for environmental responsibility, their strategic positioning must be generalized at the operational level (Lee et al. 2014). Emergent theory suggests that generalizations about issues such as environmental responsibility can be achieved through a marketing doctrine - a set of principles, summarized in easy-tocommunicate rules of thumb, that draw on the company's experience to guide more consistent but flexible decision making at an operational level and improve organizational performance (Challagalla et al. 2014). This lens is particularly pertinent in our study context, because responsibility for achieving environmental goals not only lies with marketers but also spreads throughout the organization (Langan 2014). For retailing specifically, decisions made in multiple, geographically dispersed stores and the actions of various sales teams largely determine environmental goal achievement. An operational manager acts as the critical go-between, translating the marketing doctrine to inform employee decisions and actions. A marketing doctrine is emerging as an important practice for organizations, which suggests the need for close attention to two key factors: (1) the adoption or adaptation of guiding principles by non-marketers to execute the strategy through coherent decision making and (2) how the adoption of the marketing doctrine depends on the attitudinal and situational characteristics of the workforce (Challagalla et al. 2014).

The climate concept has emerged as a "missing link" between such internal and external performance parameters (Andrews and Rogelberg 2001). Climate generally refers to "the shared meaning ... members attach to the events, policies, practices and procedures they experience and the behaviors they see being rewarded, supported, and expected" (Ehrhart et al. 2013, p. 69). Policies refer to the choice of goals and means of goal attainment, procedures provide guiding principles for action, and practice pertains to implementations in daily work routines. Contemporary climate research suggests 
a linkage (or mediating) role, such that facet-specific rather than global climates reveal employees' perceptions of relevant practice and better predict organizational performance (Schneider et al. 2000; Zohar and Luria 2004). Facetspecific climates relate to the individual's situational context, rather than more remote values of the organization's culture (Ehrhart et al. 2013). Thus facet-specific climates might be regarded as framing the collective understanding and implementation of doctrine within a work unit, to reflect how policies and procedures established at the organizational level get practiced at the subunit level (Zohar and Luria 2004). Specifying climate at this facet-specific level might provide insights into why organizations struggle to align their performance with their environmental responsibility (Lee et al. 2014).

Thus, we argue that a facet-specific climate is necessary to ensure that an environmentally focused marketing doctrine gets translated, articulated, and sustained at a collective level in the operational sales context and customer-facing network of sales units. How does environmental responsibility at an organizational level translate to the operational level? De Ruyter et al. (2009) suggest that environmentally responsible behavior within boundary-spanning teams can be understood through the concept of environmental stewardship they define as "a collectively held sense of responsibility toward the environment, as reflected in the policies, procedures, and actions used during employee encounters with customers" (de Ruyter et al. 2009, p. 247). Most research on stewardship focuses on managers' responsibility for maximizing the long-term, economic wealth of their organization, but its relevance for emerging environmental responsibility concepts also has been acknowledged (Caldwell et al. 2008; Kotler 2011). Stewardship implies a willingness to take personal responsibility for a long-term benefit, even if it means subjugating personal interests in the short term (Block 1993; Davis et al. 1997; Hernandez 2012). Its application to environmental responsibility seems evident, because responsible actions bring about long-term benefits, but they must be balanced against shorter term economic goals.

At the climate level, the collective interpretation of stewardship might best be understood through the influence of social context on decision-making processes (March 1994; Weber et al. 2004). Through situational assessments of their environment, people derive appropriate rules of conduct. Formally prescribed policies and incentive and reward structures also likely shape appropriateness norms for environmental stewardship at the store level (Deutsch Salamon and Robinson 2008; March 1994). We anticipate that organizational rules can develop into responsibility norms that serve as a primary motivational force behind stewardship (de Ruyter et al. 2009). Recent research on stewardship behaviors similarly emphasizes their normative basis (Hernandez 2012). Norms link individual- to group-level behaviors: descriptive norms present ways to act in a specific situation, whereas injunctive norms represent behavioral approval (or disapproval) at a cultural level (Goldstein et al. 2008; Nejad et al. 2014). Driven by an underlying role modeling mechanism, people use others' behavior as a reference point to derive descriptive norms and decide whether to act in environmentally responsible ways (Goldstein et al. 2008). Such social heuristics can instigate moral considerations that lead to collectively beneficial behavior or, alternatively, to calculative decision modes that result in self-serving utility maximization (Tenbrunsel and Messick 1999). These social heuristics do not delineate a scripted course of action, but work units often develop shared beliefs about desirable performance behavior (Deutsch Salamon and Robinson 2008). Social norms also are most effective as drivers when their descriptive and injunctive levels align, such that organizational policy would align with daily practice.

The development of new ideas and programmatic thinking is a continuous organizational challenge, because shared mental models are necessary to expedite adaption to new ideas. With this basis, we propose a conceptualization of a climate for environmental stewardship that adopts a process focus to align with the distinctive characteristics of the retail context. Individual sales associates do not operate in isolation but instead function within a store environment marked by behavioral norms about what is appropriate, based on organizational policy and driven by the store manager. We also note the role of proximally relevant stakeholders: the store, the company, and the customer. Therefore, we define a perceived SENSclimate within a retail context as follows:

The extent to which sales associates perceive (1) a collective sense of responsibility toward the environment, which may require them to subjugate their personal and collective interests to help limit the environmental impact of their company, (2) that they contribute to and promote initiatives that help improve the company's environmental performance; and (3) that they promote environmentally responsible choices amongst a wider range of customers while still trying to meet their demands.

\section{Antecedents and impacts of a SENS-climate}

Sales associates' environmentally friendly behaviors should flourish best in a work environment in which environmental responsibility is appropriate, that is, in a SENS-climate. We therefore develop hypotheses about the antecedents of a SENS-climate, which serve as a basis for translating an environmental marketing doctrine into decisions that sales associates make in their daily work. We conceptualize these antecedents in terms of: (1) articulation, that is, store managers' 
role modeling through task-oriented actions that signal priority of principles and their collective interpretation in a retail context, and (2) sustainability, or relationship-oriented practices that moderate the effects of articulation on SENS-climate formation. We also explore the impacts of a SENS-climate on performance.

\section{Articulation of the prioritization of environmental principles}

Leaders play an important role in developing shared perceptions, to steer employees toward behaviors that serve longterm, collective benefits (Hernandez 2012; Yaffe and Kark 2011). Sales associates can use store managers as role models and observe the task-oriented actions these managers perform to achieve the objectives that characterize their own jobs. With their task-oriented actions, leaders articulate the relative priorities of different goals and indicate which behaviors are appropriate (Casimir 2001; Zohar and Luria 2004). We focus on store managers' task-oriented actions that indicate the relative priority of environmental responsibility compared with other goals.

In understanding task-oriented actions, it is important to distinguish two underlying attributes: their pattern orientation of actions and their pattern variability of actions (Zohar and Luria 2004). Stewardship scholars similarly discriminate between direction and clarity that leaders provide to followers (de Ruyter et al. 2009; Donaldson and Davis 1991). Pattern orientation, akin to direction, indicates the mean level of prioritization of one role facet or another (e.g., green versus regular sales). Pattern variability, similar to clarity, represents the extent to which similar events (or contingencies) result in the same supervisory actions, in terms of relative priorities. That is, it represents the variance of the extent to which similar situations elicit altered priorities. Orientation and variability can affect climate differently (Zohar and Luria 2004). In operationalizing phenomena at store levels (e.g., environmental orientation), recent studies also emphasize the need to assess an overall average score to reflect the degree to which a phenomenon occurs, distinct from the variability of this score, which reflects the quality or strength of the phenomenon (de Ruyter et al. 2009).

First, we assess a leader's pattern orientation, or the extent to which a store manager's decision patterns articulate the prioritization of environmental responsibility relative to other goals (e.g., maximizing financial performance, limiting operational costs, optimizing personal gain), in line with the guiding principles of the company. For an adequate understanding of appropriate behaviors, sales associates must engage in active sense-making processes by repeatedly observing manager actions that reflect their prioritization of one role facet over another; this is termed pattern orientation (Zohar and Luria 2004). In our study context, when a store manager's actions repeatedly make environmental policies contingent on operational efficiency or financial performance, in situations where these goals are at odds (termed as low pattern orientation), sales associates learn that operational and financial performance have priority, regardless of their leader's voiced concern for the environment. If a store manager acts as a steward by making a trade-off in operational or financial performance for the sake of improving a store's environmental performance (termed as high pattern orientation), sales associates infer that environmental responsibility is an appropriate course of action and are more likely to act as environmental stewards themselves (Block 1993; Hernandez 2008, 2012). Because a manager's pattern orientation can help foster a climate in which environmentally responsible actions become the perceived norm, we posit:

H1: When store managers display higher pattern orientation, this leads to higher perceived SENS-climate.

Second, we examine the leader's pattern variability, or the relative strength or quality of the manager's commitment to an environmental orientation, exhibited by the boundaries within which the store manager's prioritization of environmental responsibility predominates or not, across different situations. Sales associates can derive information about priorities and appropriate actions by observing their store managers' actual decisions, but they also gain implicit cues from patterns of choices over time that signal the strength of the environmental orientation. Variability in decision patterns can be detrimental though, because creating a SENS-climate requires store managers to be consistent in their prioritization of environmental responsibility across similar situations. If store managers behave consistently (termed as low pattern variability), employees can easily detect their managers' action patterns and deduce which actions are appropriate (March 1994; Zohar and Luria 2004). If store managers instead give priority to environmental responsibility in one situation but operational efficiency or financial performance in another similar situation (termed as high pattern variability), it can confuse sales associates, hinder identification of appropriate behaviors, and impede the formation of shared norms in the working climate (Weber et al. 2004). Variability in a leader's task-oriented actions also might encourage sales associates to rely on other situational cues, such as incentives. Therefore, we hypothesize:

H2: When store managers display higher pattern variability, this leads to lower perceived SENS-climate.

\section{Sustainability of the prioritization of environmental principles}

Sustaining the prioritization of environmental principles should be facilitated by relationship factors. Consistent 
evidence shows that leadership style shapes facet-specific climates (Zohar and Tenne-Gazit 2008), and we account for this baseline effect by hypothesizing:

H3: Perceptions that a store manager uses transformational leadership practices lead to higher perceived SENS-climate.

Importantly, we look beyond this established, direct relationship to posit that relationship-oriented leadership practices moderate the effects of a store manager's task-oriented actions on the perceived SENS-climate. Transformational leaders tend to be accepted as role models and have the capacity to explain their motives (Berson and Avolio 2004; Walumbwa et al. 2008). Thus they can help strengthen sales associates' understanding of their pattern orientation and limit confusion created by any pattern variability. This ability is particularly pertinent for developing a sustainable climate for prioritization of environmental responsibility. A shared managerial vision should encourage sales associates to develop an intrinsic interest in environmental stewardship, whereas extrinsic incentives fail to foster long-term perspectives (Bass 1999; Morhart et al. 2009). Therefore, transformational leadership practices should amplify the positive effects of store managers' pattern orientation and attenuate the negative effects of their pattern variability on the perceived SENS-climate:

H4: Perceptions that a store manager uses transformational leadership practices will (a) strengthen the positive effect of the store manager's pattern orientation on perceived SENS-climate, whereas they will (b) diminish the negative effect of pattern variability on perceived SENS-climate.

It also takes some time for sales associates to make sense of their managers' behaviors and for leader-follower relationships to develop (Hernandez 2012; March 1994). Sales associates must become accustomed to behavioral norms and develop requisite skills to comply with those norms, so store managers must make continuous investments (Hernandez 2012). Employees with a longer tenure are more likely to identify with the company and accept norms that prescribe stewardship actions (Donaldson and Davis 1991). With our focus on the role of store managers' actions in creating such norms, we propose that the length of the relationship between the store manager and a sales associate (dyadic tenure) might be an important moderator of perceptions of a SENS-climate. The dyadic leader-follower relationship influences information exchanges and thus a follower's interpretation of a leader's behavior (Wieseke et al. 2009). The accuracy of interpersonal perceptions also increases with relationship length, which should improve interpretations of the manager's behavior (Homburg et al. 2009). Dyadic tenure then should amplify the potential positive effect of a store manager's pattern orientation and transformational leadership on the SENS-climate but diminish the potential negative effect of any pattern variability. Formally:

H5: When the store manager-sales associate dyadic tenure is longer, the positive effects of (a) pattern orientation and (b) transformational leadership on perceived SENSclimate will be stronger, whereas the negative effect of (c) pattern variability on perceived SENS-climate will be weaker.

\section{Impact of the SENS-climate on performance}

An important question that remains is how the stimulation of a SENS-climate likely affects sales associates' performance. Consumer adoption of eco-innovations has been weak, likely because they demand fundamental shifts in consumers' mindset, from short- to long-term goals (Hofstra and Huisingh 2014), which makes the sales task even more demanding. Previous research fails to establish any direct impact of environmental responsibility on overall bottom-line performance (de Ruyter et al. 2009), but we propose more subtle effects of the SENS-climate on sales. In particular, norms that support environmentally responsible actions should increase sales associates' attention to green products and willingness to encourage customers to consider environmental performance in their decision-making process. Because a SENS-climate suggests a long-term perspective, sales associates should be more likely to educate customers about the long-term benefits of green products and how they outweigh perceived disadvantages or risks associated with innovative products. With this sales approach, sales associates can meet customer needs by selling green products, which usually sell at higher margins (Best Buy Co. Inc 2010; Euromonitor International 2010a; Prindle 2010). At the individual sales associate level, we thus expect increased sales of green products and higher margins, but because the extra attention to green products likely reduces attention to regular products, sales of regular products may decrease. Overall:

H6: Perceived SENS-climate has a positive effect on (a) sales of green products, and (b) margins, while it has a negative effect on the (c) sales of regular products.

We present our hypotheses in Fig. 1, which represents our conceptual framework. 


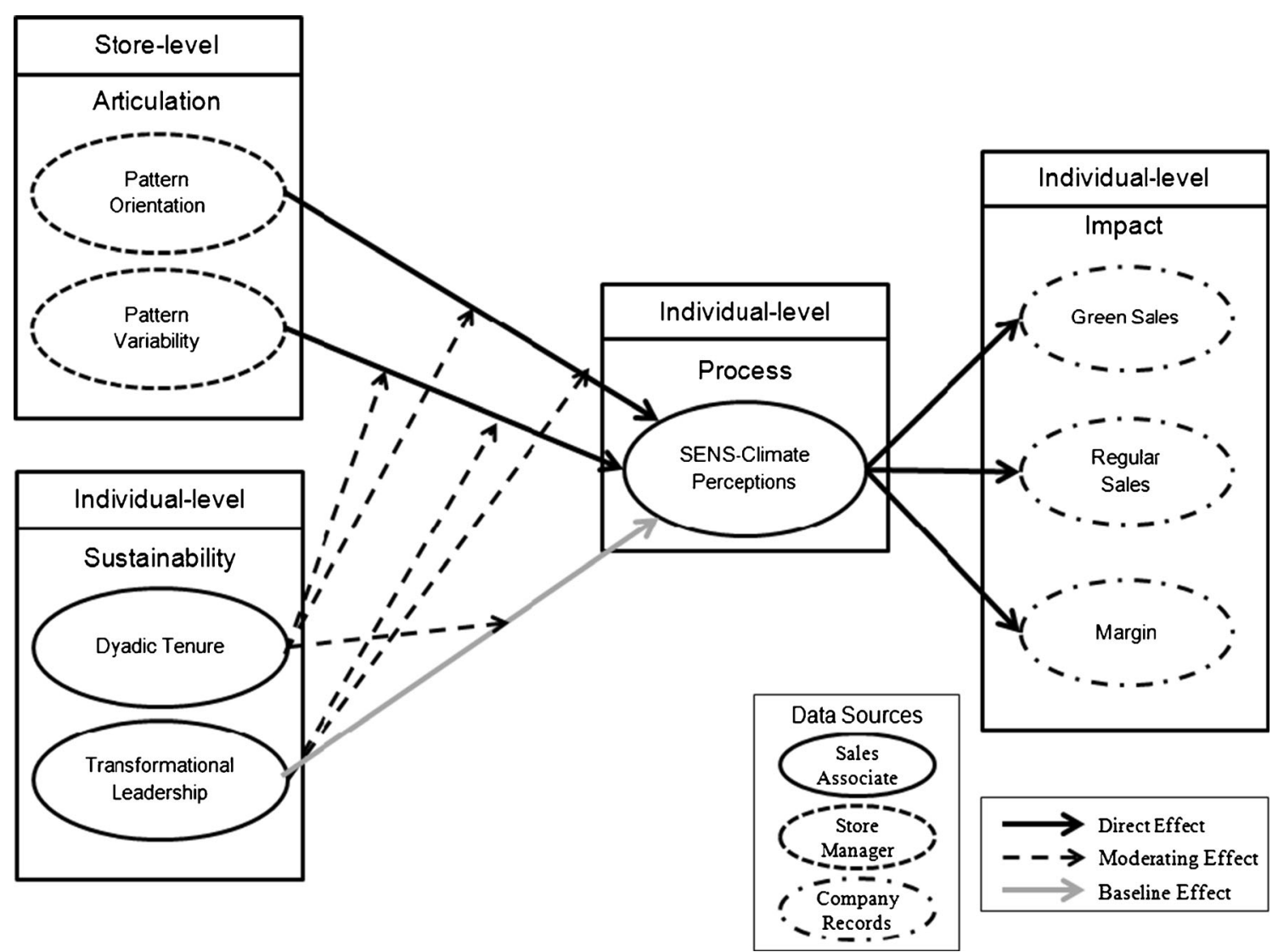

Fig. 1 Conceptual framework of antecedents and impact of SENS-climate

\section{Empirical study}

\section{Research sample and approach}

We collected data from 36 outlets of a mid-sized, familyowned and -run European electronics retailer that sells a full range of electronic and household appliances. All stores were based in one European country. This retailer has experienced increasing consumer demand for and manufacturers' supply of green products, reflecting the rapid eco-innovations in the electronic and household appliance industry and increasing consumer education (Electrolux 2013; WWF 2014). Internet retailers have claimed a share of the market though, increasing both price-based competition and customers' expertise. The two main offline competitors of our focal firm represent two strategic extremes: one competes solely by offering the lowest price, whereas the other provides the highest quality in terms of environmentally friendly products and unapologetically charges premium prices for them. The focal firm traditionally has been service oriented; these market developments have put it under increasing pressure to compete on both fronts and offer a quality product (environmentally friendly where possible) at the best price. The firm's strategic juxtaposition relative to its two biggest competitors was a primary motivation for its study participation, in that it sought to understand how to infuse environmentally friendly goals with performance objectives.

The retailer employs 650 people, $60 \%$ of whom work in stores as store managers or sales associates. Store managers' and sales associates' incomes are fixed monthly salaries, on top of which they can earn small commissions on sales. The rate of commissions is uniform across stores, as specified by headquarters. The retailer has no formal policy for actively promoting the sales of green products through commissions, so these sales probably depend on store- or individual-level processes. Store managers' main tasks involve supervising and guiding sales associates, managing according to key performance indicators, and designing store presentations. They spend substantial time on the shop floor and also deal with customers. Sales associates are responsible for customer contacts, including giving advice, providing service, and selling products. Employees are in regular contact through their shared work environment and regular staff meetings led by store managers to discuss objectives and performance.

The data for this study are cross-sectional; however, they are also based on multiple data sources and multiple measurement procedures (Podsakoff et al. 2003). We used company records to gather data about the outcomes and control variables, an online questionnaire with stem scenarios to assess the pattern orientation and pattern variability of store 
managers, and a separate online survey of sales associates to measure transformational leadership, dyadic tenure, and SENS-climate perceptions. These multiple data sources offer the added advantage of reducing hypothesis guessing and limiting potential demand effects (Shimp et al. 1991).

In cooperation with the retailer's management team across the 36 stores, we approached all store managers and sales associates and requested their participation. To limit social desirability influences, all participants received an introductory letter in which we assured them that their individual data would be treated confidentially and not be accessible to anyone but the researchers and that the results would be presented only at an aggregate level. We also limited the information provided about the survey objectives, to avoid hypothesis guesses. Store managers read that their online survey aimed to find out how they made decisions when faced with dilemmas; sales associates answered questions about their work environment (without any reference to store managers' tradeoffs) in a separate online survey. Each respondent used an individual user name and password, so we could link sales associates' responses to their store managers' responses and the performance data, without any involvement by internal firm personnel. After follow-up telephone calls to each store, we received complete survey data from 36 store managers and 182 sales associates (nested in the 36 stores), for response rates of $84 \%$ and $57 \%$, respectively. For the majority of stores $(n=25) 3$ to 5 sales associates participated; the minimum was 2 sales associates for one store, and the maximum was 16 sales associates in another store.

Among the store manager sample, 35 (97\%) were men, and 23 (64\%) were older than 40 years. Furthermore, 24 (67\%) of the store managers had acted in this function for more than 5 years, and $22(61 \%)$ had managed their current store for more than 3 years. In the sales associate sample, 147 (81\%) were men, $126(69 \%)$ worked full-time, and $78(43 \%)$ were younger than 30 years, but $51(28 \%)$ were older than 40 years. In addition, 124 (68\%) had more than 5 years' experience in sales, and 98 (54\%) had worked in the current store for more than 3 years.

\section{Store-level measures}

Pattern orientation and pattern variability Store managers completed a set of eight stem scenarios that served to evaluate their pattern orientation and pattern variability. Each stem scenario represented a typical store situation in which a store manager would need to choose between taking environmental responsibility and improving operational efficiency. This procedure uses scripts to proxy for actual behavior, because scripts "provide mental representations of goal-directed behavior chains in well-known situations and serve as repositories of behavioral plans" (Zohar and Luria 2004, p. 326). The scripts encompass the multiple potential paths to a specific goal, and situational conditions and past experience influence path selection (Wofford and Goodwin 1990). When some paths dominate, it results in stable, contingency-based action patterns, or "'if-then' decision rules for each script" (Zohar and Luria 2004, p. 326). By recording store managers' choices in simulated events, representative of regular job situations, we can capture these proxies for their action patterns. For this study, the pertinent events are occurrences that sales associates can observe and that require the store manager to choose between environmental responsibility and operational efficiency. To assess a store manager's pattern orientation, we observe the manager's prioritization of environmental responsibility over efficiency across a sample of events. Pattern variability is observed by assessing differences in prioritization across these events. To develop our stem scenarios, we first conducted indepth interviews with a senior manager, six store managers, and five sales associates to identify typical, suitable events. From these interviews we developed ten stem scenarios, which we then discussed with two upper-level managers to ensure they were reflective of store managers' tasks. We made some minor adjustments on the basis of their feedback. Then six academic researchers not involved in the research project reviewed the adapted versions of the ten stem scenarios, with detailed information we provided about the purpose of the scenarios. We used their feedback to make further improvements. Finally, we again consulted upper-level managers, who selected the eight stem scenarios that represented the most familiar, frequently occurring events. These scenarios reflect a variety of tasks that store managers regularly face (e.g., customer contacts, advising sales associates, assortment composition, store presentation).

In the final set of scenarios in the online survey sent to store managers, each scenario starts by describing a situation in which the store manager faces a choice between environmental responsibility and operational efficiency. Then four scenes that differ with regard to the environmental benefits and operational costs associated with the decision follow. We differentiate low and high environmental benefits (LEB vs. HEB) and low and high operational costs (LOC vs. HOC), so the four scenes correspond to four different combinations (scene $1=$ HEB-LOC, scene 2=LEB-LOC, scene $3=$ HEB-HOC, scene $4=$ LEB-HOC). For each scene, the store manager chose between acting environmentally responsibly (most environmentally beneficial option, with higher operational costs) and acting efficiently (least environmentally beneficial option, with lower operational costs).

After making choices for all four scenes, store managers considered the same scenes again, with a contingency added to each description. The contingency depended on their first choice made. That is, if a manager had chosen to act environmentally responsibly at first, the contingency entailed an ordinal, within-scene decrease of environmental benefits or increase in operational costs (i.e., acting environmentally 
responsibly became less attractive). If a manager had chosen to act operationally efficiently at first, the contingency entailed an ordinal, within-scene increase in environmental benefits or decrease in operational costs (i.e., acting environmentally responsibly became more attractive). The store managers then had to make new choices for each scene, taking the contingency into account. The online survey was programmed to use each manager's first choice as a filter and determine the applicable contingency for each scene. In total, each store manager made eight choices for each of the eight stem scenarios (four choices in step 1 and four choices in step 2). An example stem scenario is in Fig. 2 (the other stem scenarios are in the Web Appendix).

To calculate (1) the pattern orientation and (2) pattern variability scores for each manager, we used a two-step scoring procedure (Zohar and Luria 2004). First, we measured the orientation that managers displayed for each scene on a fourpoint ordinal scale, according to their first and second scenario choices. If a store manager chose to act environmentally responsibly both times in response to the same scene (i.e., despite the decreased attractiveness of acting environmentally responsibly), he or she exhibited a high priority for environmental responsibility over operational efficiency, scoring 4. An initial choice to act environmentally responsibly followed by a choice to act operationally efficiently resulted in a score of 3 . An initial choice to act operationally efficiently followed by a choice to act environmentally responsibly (i.e., due to the increased attractiveness of acting responsibly) ranked as 2. Finally, if a store manager chose to act operationally efficiently both times, she or he exhibited a low for environmental responsibility compared with operational efficiency and earned a score of 1 .

Second, we incorporated each scene's context in the scoring procedure, because it would be easier to act environmentally responsibly in some scenes. We assigned weights, based on a three-point ordinal scale, to each scene to reflect the environmental benefits-operational costs trade-off. In scene 1 , acting environmentally responsibly was easier, because it featured high environmental benefits and low operational costs (HEB-LOC). In scene 4, acting environmentally responsibly was harder, because it was characterized by low environmental benefits and high operational costs (LEB-HOC). If a store manager acted environmentally responsibly in scene 4 (LEB-HOC), it offered a stronger indication of environmental
Fig. 2 Example stem scenario 1
A lot of energy is used in your store, and you consider taking action to reduce the energy consumption for the benefit of the environment. You know that the biggest energy consumers in your store are the televisions that are turned on all day. To limit energy consumption, you could choose not to turn all televisions on. However, televisions that are turned off are harder to sell. What would you do in the following scenes?

Scene 1: You can reduce your energy use by $6 \%$ (a lot of environmental gain) if you turn $10 \%$ of your televisions off.

Do you turn this percentage of your televisions off? (No/Yes)

Scene 2: You can reduce your energy use by 3\% (a bit of environmental gain) if you turn $10 \%$ of your televisions off.

Do you turn this percentage of your televisions off? (No/Yes)

Scene 3: You can reduce your energy use by $6 \%$ (a lot of environmental gain) if you turn $25 \%$ of your televisions off.

Do you turn this percentage of your televisions off? (No/Yes)

Scene 4: You can reduce your energy use by 3\% (a bit of environmental gain) if you turn $25 \%$ of your televisions off.

Do you turn this percentage of your televisions off? (No/Yes)
If you answered Yes to any of the above, how would you react if you consider this extra information?

It is winter. Turning the televisions off will lower the temperature in your store, which means you need to turn the heat up. This reduces your energy savings by $1 \%$ compared to the scene description above.

Do you turn the televisions off?

Scene 1: (No/Yes)

Scene 2: (No/Yes)

Scene 3: (No/Yes)

Scene 4: (No/Yes) 
prioritization than would acting responsibly in scene 1 (HEBLOC). Thus, we assigned a weight of 3 to scene 4 (LEBHOC) and a weight of 1 to scene 1 (HEB-LOC). The other two scenes (LEB-LOC, HEB-HOC) represented balances between the environmental benefits and operational costs, so we assigned both scenes 2 and 3 weights of 2 .

Each store manager's pattern orientation score per stem scenario was determined by (1) multiplying scenario weighting with the orientation that each store manager displayed per scene and (2) summing these scores for all four scenes for each stem scenario. The mean scores across the eight stem scenarios represented the store manager's final pattern orientation (i.e., high mean scores indicated high pattern orientation). The standard deviation (SD) across all stem scenarios represents a manager's pattern variability (i.e., high SD indicates high variability).

Other measures After store managers completed the stem scenarios, they indicated their gender (female $=0$, male $=1$ ), age (in years), and tenure as a store manager in general and as a manager of their current store (number of years). Two other store-level variables came from company records. Store size represents the number of sales associates working in the store, and region represents the area in which the store is located. We used tenure in the current store, store size, and region (dummy variables) as controls in our analyses.

\section{Individual-level measures}

Perceived SENS-climate For our measure of the perceived SENS-climate, we adapted a scale to measure a collective sense of environmental stewardship from de Ruyter et al. (2009). Their scale does not reflect our multidimensional conceptualization of environmental stewardship for the retail context, so we adapted their items to fit our conceptualization. Specifically, we extended the scale with insights gained from 14 comprehensive interviews with company employees. The final scale for measuring SENS-climate perceptions consisted of 11 items, reflecting the extent to which sales associates perceive (1) a collective sense of responsibility toward the environment (5 items), (2) that they contribute to and promote initiatives that help improve their company's environmental performance (3 items), and (3) that they promote environmentally responsible choices among a wider range of customers while still trying to meet their demands (3 items). The seven-point scale ranged from "strongly disagree" (1) to "strongly agree" (7). The higher-order factor consisted of the three reflective first-order constructs that represented our three SENS-climate dimensions.

Transformational leadership To measure transformational leadership, we assessed individual sales associates' perceptions of their store managers' behaviors, using the original scale from Avolio and Bass, the MLQ, Form 5X-short, (1995). In line with previous studies (Menguc and Auh
2008; Walumbwa et al. 2008), we operationalize transformational leadership as a higher-order factor with four reflective first-order constructs: idealized influence (6 items), inspirational motivation (3 items), intellectual stimulation ( 3 items), and individual consideration ( 3 items). We assessed the measurement properties of our SENS-climate and the transformational leadership constructs simultaneously with a confirmatory factor analysis (CFA). Both constructs were included as higher-order factors, with three and four underlying first-order constructs, respectively. We used LISREL 8.80 (Jöreskog and Sörbom 2006) to obtain the estimates. The analysis revealed a good fit to the data: $\chi^{2}(293)=505.249, p<.001$, confirmatory fit index $(\mathrm{CFI})=.97$, incremental fit index $(\mathrm{IFI})=.97$, nonnormed fit index $(\mathrm{NNFI})=.96$, root mean square error of approximation $($ RMSEA $)=.060$, and standardized root mean square residual $(\mathrm{SRMR})=.063$. We evaluated the convergent validity of the measures by assessing whether the manifest variables loaded significantly and adequately on the hypothesized latent variable (Anderson and Gerbing 1988). The observed standardized loadings were significant $(\alpha=.05)$. We also calculated the composite reliability (CR) and average variance extracted (AVE) for both measures. Both values exceeded their recommended cut-off values of .7 and .5 , respectively, for both the SENS-climate $(\mathrm{CR}=.92 ; \mathrm{AVE}=.80)$ and transformational leadership $(\mathrm{CR}=.95 ; \mathrm{AVE}=.84)$ measures (Fornell and Larcker 1981). Finally, we assessed discriminant validity by comparing the square root of the AVE with the (attenuated) correlation between the latent variables that represent SENS-climate and transformational leadership (Fornell and Larcker 1981). The square root of the AVE of both latent variables exceeded the (attenuated) correlation between them, in support of discriminant validity (see the Appendix Table 4 for details).

Dyadic tenure We measured store manager-sales associate dyadic tenure in years by asking each sales associate how long they had been working with the same store manager.

Impact measures We examined the relationships between SENS-climate perceptions and performance at the individual level by using objective data from the company's records about sales associates' performance on achieved margins and sales. Reflecting the reality that "no consumer product has a zero impact on the environment, in business, the terms 'green product' and 'environmental product' are used commonly to describe those that strive to protect or enhance the natural environment by conserving energy and/or resources and reducing or eliminating use of toxic agents, pollution, and waste" (Ottman et al. 2006, p. 24), and that most of an appliance's environmental impact resides in the use phase, we split the sales figures into sales of more energy efficient products (green sales) and sales of less energy efficient products (regular sales). The distinction is grounded in the actual 
practices of our focal retailer, which in turn reflects the EU labeling scheme (similar to the U.S. Energy Star label) for designating a product's energy efficiency.

Other measures We gathered sales associates' background information: gender (female $=0$, male $=1$ ), work status (parttime $=0$, full-time $=1$ ), age (in years), tenure as sales associate in general, and tenure in the current store (number of years).

\section{Analyses}

To estimate the effects of the antecedent variables on the perceived SENS-climate, we specified hierarchical linear regression models, using MLwiN 2.22 (Rasbash et al. 2010). We used this approach because our data are hierarchical (i.e., each store manager supervised multiple sales associates). Two levels of aggregation exist: the individual sales associate level and the store (manager) level. Conventional statistical techniques (e.g., ordinary regression analysis) ignore this hierarchical structure and may produce incorrect results (Raudenbush and Bryk 2002). Hierarchical linear models (or multilevel models) are an effective approach to deal with hierarchically nested data structures. First, hierarchical linear analysis estimates the relationships within a particular hierarchical level, as well as relationships between or across hierarchical levels simultaneously. Second, it accounts for the statistical dependence between members of the same unit (e.g., sales associates supervised by the same store manager). Third, the multilevel model separates sampling error due to variation between and within units (Raudenbush and Bryk 2002).

In the first step, we included the control variables at the individual and store levels (Model 1). In the second step, we added the antecedent variables (Model 2). In the third step, we specified the interactions among antecedent variables (Model 3 ) and obtained the following multilevel equation ${ }^{1}$ :

$$
\begin{aligned}
& \text { SENS }_{i j}=\gamma_{00}+\gamma_{10} \text { GENDER }_{i j}+\gamma_{20} \text { WORK }_{i j}+\gamma_{30} \text { TENE }_{i j}+\gamma_{40} \text { TENDY }_{i j} \\
& +\gamma_{50} \text { TLEAD }_{i j}+\gamma_{01} \text { STSIZE }_{j}+\gamma_{02} \text { REGD }_{j}+\gamma_{03} \text { REGD }_{j}+\gamma_{04} \text { REGD4 }_{j} \\
& \left.+\gamma_{05} \text { TENM }_{j}+\gamma_{06} \text { PATOR }_{j}+\gamma_{07} \text { PATVAR }_{j}+\gamma_{60} \text { TENDY }_{i j} \times \text { TLEAD }_{i j}\right)_{i j} \\
& +\gamma_{70}\left(\text { TENDY }_{i j} \times \text { PATOR }_{j}\right)_{i j}+\gamma_{80}\left(\text { TENDY }_{i j} \times \text { PATVAR }_{j}\right)_{i j} \\
& +\gamma_{90}\left(\text { TLEAD }_{i j} \times \text { PATOR }_{j}\right)_{i j}+\gamma_{100}\left(\text { TLEAD }_{i j} \times \text { PATVAR }_{j}\right)_{i j}+u_{0 j}+e_{i j} .
\end{aligned}
$$

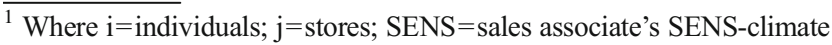
perceptions; GENDER = sales associate's gender; WORK=sales associate's work time; TENE= sales associate's tenure in stores; TENDY $=\mathrm{dy}-$ adic tenure between a sales associate and the store manager; TLEAD= sales associate's perception of the store manager's transformational leadership practices; STSIZE=store size, as the number of sales associates working in the store; REGD2, REGD3, \& REGD4=dummy variables of store regions; TENM=store manager's tenure as manager of the store; $\mathrm{PATOR}=$ store manager's pattern orientation; $\mathrm{PATVAR}=$ pattern variability; $\gamma_{00}=$ intercept; $\gamma_{10} \ldots \gamma_{100}=$ regression coefficients; $e_{i j}=$ individuallevel error term; and $\mathrm{u}_{\mathrm{oj}}=$ unique variation of group $\mathrm{j}$ from the intercept $\left(\gamma_{00}\right)$, after partialling out the effects of all store-level regression coefficients $\left(\gamma_{01} \ldots \gamma_{07}\right)$.
}

We grand mean-centered the first-order variables before estimating our models, which also served as the basis for creating the interaction terms (Aiken and West 1991).

We estimated the effects of the perceived SENSclimate on performance outcomes by specifying a multivariate hierarchical linear regression model, instead of separate univariate multilevel regression models, which offers several advantages. In particular, it provides an overall model fit statistic (Chi-square test), accounts for relationships among the dependent variables, is generally better in controlling for type-I errors, and possesses stronger power (Hox 2002). Three hierarchical levels were specified: Level 1 refers to the dependent variables indexed by $\mathrm{h}=1, \ldots, \mathrm{m}$; Level 2 is individual sales associates $\mathrm{i}=1, \ldots, \mathrm{n}_{\mathrm{j}}$; and Level 3 represents stores $\mathrm{j}=1, \ldots$, $\mathrm{N}$. Each assessment of a given outcome variable for a sales associate within a certain store thus is indicated by a specific line in the data matrix that contains the values $\mathrm{i}, \mathrm{j}, \mathrm{h}, \mathrm{Y}_{\mathrm{hij}}, \mathrm{x}_{1 \mathrm{ij}}$, and all other predictors. To formulate the multivariate regression model as a hierarchical linear model, we used dummy variables $d_{1}$ to $d_{m}$ to indicate the outcomes (green sales, regular sales, and margin). The dummy $\mathrm{d}_{\mathrm{h}}$ equals 1 or 0 , depending on whether the data line refers to outcome variable $\mathrm{Yh}$ or another outcome variable, as expressed by Eq. 2:

$\mathrm{d}_{\text {shij }}= \begin{cases}1 & \mathrm{~h}=\mathrm{s}, \\ 0 & \mathrm{~h} \neq \mathrm{s} .\end{cases}$

With these dummies, we can integrate the regression equations for the $\mathrm{m}$ outcome variables into a single, three-level hierarchical model by the following expression:

$Y_{\text {hij }}=\sum_{s=1}^{m} \gamma_{0 s} d_{\text {shij }}+\sum_{k=1}^{p} \sum_{s=1}^{m} \gamma_{k s} d_{s h i j} x_{k i j}+\sum_{s=1}^{m} u_{s j} d_{s h i j}+\sum_{s=1}^{m} e_{s i j} d_{s h i j}$.

All variables (including the constant) are multiplied by the dummy variables. In the sums over $s=1, \ldots, m$, only $s=h$ renders a contribution; all other terms are removed. We included SENS-climate as an antecedent while controlling for sales associates' gender, work time, and tenure; store managersales associate dyadic tenure; and store size, region, and store manager tenure. We also specified individual- and store-level relationships among the dependent variables, expressed as $\operatorname{var}\left(\mathrm{e}_{\mathrm{hij}}\right)=\sigma_{\mathrm{hh}}$, and cov $\left(\mathrm{e}_{\mathrm{hij}}, \mathrm{e}_{\mathrm{h}^{\prime} \mathrm{ij}}\right)=\mathrm{e}_{\mathrm{hh}}$ and $\operatorname{var}\left(\mathrm{u}_{\mathrm{hj}}\right)=\tau_{\mathrm{hh}}$, and $\operatorname{cov}\left(u_{h j}, u_{h^{\prime} j}\right)=\tau_{h h^{\prime}}$, respectively. By including the covariance terms, we allowed the dependent variables to co-vary at both the individual and the store level.

Finally, we examined the mediating role of the SENSclimate between store managers' action patterns and performance outcomes. Estimating this mediation for transformational leadership requires a 1-1-1 (e.g., independent variable level, mediating variable level, and dependent variable level) model (Bauer et al. 2006; Preacher and Selig 2010). 
Estimating its mediating role for the effects of pattern orientation and pattern variability instead involves 2-1-1 models (cf., Bauer et al. 2006). Following MacKinnon et al. (2004), Bauer et al. (2006) propose a Monte Carlo mediation approach to construct confidence intervals for hierarchical linear models, which we employed in our mediation analysis (Preacher and Selig 2010).

\section{Results}

We present means, standard deviations, and intercorrelations with regard to our focal variables in Table 1 and the findings of our multilevel analyses in Table 2. Our antecedent model, which includes pattern orientation, pattern variability and transformational leadership (Model 2), provides a better fit $\left(\Delta \chi^{2}(3)=25.071, p<.01\right)$ than the control Model 1; adding the antecedent variables significantly improved the model. In the interaction Model 3, we included the interaction terms of transformational leadership with pattern orientation and pattern variability and of dyadic tenure with pattern orientation and variability and transformational leadership and thus obtained a significant increase in fit compared with Model 2 $\left(\Delta \chi^{2}(5)=16.962, p<.01\right)$. Specifying the interactions contributed substantially to predictions of a sales associate's perceptions of the SENS-climate. These results provided initial support for our proposed model, specified within our study context.
As Model 3 shows a good fit with the data and is the most complete model that contains the results for all hypothesized effects, we refer to the findings obtained in this model. Model 3 reveals a positive effect of the store manager's pattern orientation on the SENS-climate $(\beta=.300, p<.01)$ but a negative effect of the manager's pattern variability $(\beta=-.389, p<.01)$, in support of $\mathrm{H} 1$ and $\mathrm{H} 2$. In line with $\mathrm{H} 3$ we find a significant, positive baseline effect of transformational leadership on SENS-climate perceptions $(\beta=.266, p<.01)$. Contrary to our expectations, store managers' transformational leadership did not moderate either the positive effect of pattern orientation $(\beta=-.104, \mathrm{~ns})$ or the negative effect of pattern variability $(\beta=$ $-.022, \mathrm{~ns}$ ) on the SENS-climate, so we must reject H4a and $\mathrm{H} 4 \mathrm{~b}$. Dyadic tenure strengthened the effects of pattern orientation $(\beta=.257, p<.01)$ and transformational leadership $(\beta=.191, p<.05)$ on SENS-climate perceptions, in support of $\mathrm{H} 5 \mathrm{a}$ and $\mathrm{H} 5 \mathrm{~b}$. As the interaction between dyadic tenure and pattern orientation illustrates, with longer dyadic tenures, the effect of pattern orientation on the SENS-climate is stronger (Fig. 3). Conversely, we found no evidence of dyadic tenure's moderation of the negative effect of pattern variability on SENS-climate ( $\beta=-.138$, ns), so no support for H5c.

We also estimated the effects of the perceived SENSclimate on performance outcomes. It has positive effects on green sales $(\beta=.129, p<.05)$ and margins $(\beta=.178, p<.01)$ but a significant negative effect on sales of regular products $(\beta=-.152, p<.05)$. These results supported H6a-c.

Table 1 Means, standard deviations, and intercorrelations

\begin{tabular}{|c|c|c|c|c|c|c|c|c|c|c|c|c|c|c|}
\hline Variables & $\mathrm{M}$ & $\mathrm{SD}$ & 1 & 2 & 3 & 4 & 5 & 6 & 7 & 8 & 9 & 10 & 11 & 1213 \\
\hline \multicolumn{15}{|l|}{ Store-level variables } \\
\hline 1. Store size & 8.19 & 6.07 & - & & & & & & & & & & & \\
\hline 2. Manager tenure & 5.71 & 5.01 & .03 & - & & & & & & & & & & \\
\hline 3. Pattern orientation & 15.06 & 2.65 & .02 & .1 & - & & & & & & & & & \\
\hline 4. Pattern variability & 6.52 & 2.01 & .26 & -.06 & $.56^{* *}$ & - & & & & & & & & \\
\hline \multicolumn{15}{|l|}{ Individual-level variables } \\
\hline 5. SENS-climate & 3.92 & 1.17 & -.04 & -.02 & -.03 & $-.26 * *$ & - & & & & & & & \\
\hline 6. Gender & .81 & .39 & -.11 & -.03 & .07 & -.03 & -.09 & - & & & & & & \\
\hline 7. Work time & .68 & .47 & -.05 & .03 & .06 & .11 & -.03 & $.30^{* *}$ & - & & & & & \\
\hline 8. Employee tenure & 5.02 & 4.8 & $.16^{*}$ & .08 & .03 & .09 & .0 & -.04 & .07 & - & & & & \\
\hline 9. Dyadic tenure & 3.74 & 3.46 & .06 & $.28 * *$ & .05 & $.18^{*}$ & -.05 & -.11 & $.17 *$ & $.52 * *$ & - & & & \\
\hline 10. Transform. leadership & 3.52 & .61 & $.15^{*}$ & .1 & -.09 & $-.18^{*}$ & $.24 * *$ & $-.16^{*}$ & .0 & .06 & .06 & - & & \\
\hline 11. Green sales ${ }^{\mathrm{a}}$ & N.A. & .08 & -.05 & -.09 & -.01 & .11 & $.24 * *$ & $.45^{* *}$ & $.15^{*}$ & -.11 & .07 & - & & \\
\hline 12. Regular sales ${ }^{\mathrm{a}}$ & N.A. & .07 & $-.17 *$ & -.01 & .03 & $-.15^{*}$ & $.18^{*}$ & .04 & $-.15^{*}$ & $-.15^{*}$ & -.14 & .02 & - & \\
\hline 13. $\operatorname{Margin}^{\mathrm{a}}$ & N.A. & .11 & .11 & .14 & -.01 & $.20 * *$ & $-.46^{* *}$ & $-.20 * *$ & .13 & .12 & $.20 * *$ & $-.30 * *$ & $-.39 * *$ & - \\
\hline
\end{tabular}

Correlations between two store-level variables are based on scores per store $(N=36)$; correlations between two individual-level variables and correlations between one individual-level variable and one store-level variable are based on scores disaggregated for each individual sales associate $(N=182)$

${ }^{\text {a }}$ Variables are standardized

${ }^{*} p<.05 ; * p<.01$ (two-tailed) 
Table 2 Multilevel regression analyses of antecedent-SENS-climate relationships

\begin{tabular}{|c|c|c|c|c|}
\hline \multirow[t]{2}{*}{ Variables } & \multirow{2}{*}{$\begin{array}{l}\text { Model } 1 \\
\text { Standardized coefficients }\end{array}$} & \multirow{2}{*}{$\begin{array}{l}\text { Model } 2 \\
\text { Standardized coefficients }\end{array}$} & \multicolumn{2}{|l|}{ Model 3} \\
\hline & & & Standardized coefficients & Hypothesis \\
\hline \multicolumn{5}{|l|}{ Individual-level variables: } \\
\hline Gender & -.106 & -.092 & -.066 & \\
\hline Work time & .025 & .035 & .032 & \\
\hline Employee tenure & .033 & .012 & .021 & \\
\hline Dyadic tenure & -.006 & .030 & -.006 & \\
\hline Transformational leadership & & $.249 * *$ & $.266^{* *}$ & H3 \\
\hline \multicolumn{5}{|l|}{ Store-level variables: } \\
\hline Store size & -.057 & .062 & .062 & \\
\hline Region dummy 2 & -.052 & .085 & .103 & \\
\hline Region dummy 3 & -.193 & -.052 & .007 & \\
\hline Region dummy 4 & -.158 & -.163 & -.130 & \\
\hline Manager tenure & .000 & -.107 & -.103 & \\
\hline Pattern orientation & & $.218^{*}$ & $.300 * *$ & H1 \\
\hline Pattern variability & & $-.382 * *$ & $-.389 * *$ & $\mathrm{H} 2$ \\
\hline \multicolumn{5}{|l|}{ Individual-level interaction: } \\
\hline Dyadic tenure $\times$ Transformational leadership & & & $.191 *$ & $\mathrm{H} 5 \mathrm{~b}$ \\
\hline \multicolumn{5}{|l|}{ Cross-level interactions: } \\
\hline Dyadic tenure $\times$ Pattern orientation & & & $.257 * *$ & $\mathrm{H} 5 \mathrm{a}$ \\
\hline Dyadic tenure $\times$ Pattern variability & & & -.138 & $\mathrm{H} 5 \mathrm{c}$ \\
\hline Transformational leadership $\times$ Pattern orientation & & & -.104 & $\mathrm{H} 4 \mathrm{a}$ \\
\hline Transformational leadership $\times$ Pattern variability & & & -.022 & $\mathrm{H} 4 \mathrm{~b}$ \\
\hline Increase in model fit: & $\Delta \chi^{2}(9)=5.404$ & $\Delta \chi^{2}(3)=25.071^{* *}$ & $\Delta \chi^{2}(5)=16.962 * *$ & \\
\hline
\end{tabular}

$* p<.05 ; * * p<.01$ (two-tailed)

$N=182$

Additionally, we examined the mediating role of SENSclimate between store managers' task- and relationshiporiented actions and the performance outcomes. To extend the outcome models, we added the direct effects of the two antecedent variables (pattern orientation and pattern variability), the baseline effect of transformational leadership, and the
Fig. 3 Interaction of dyadic tenure and environmental orientation

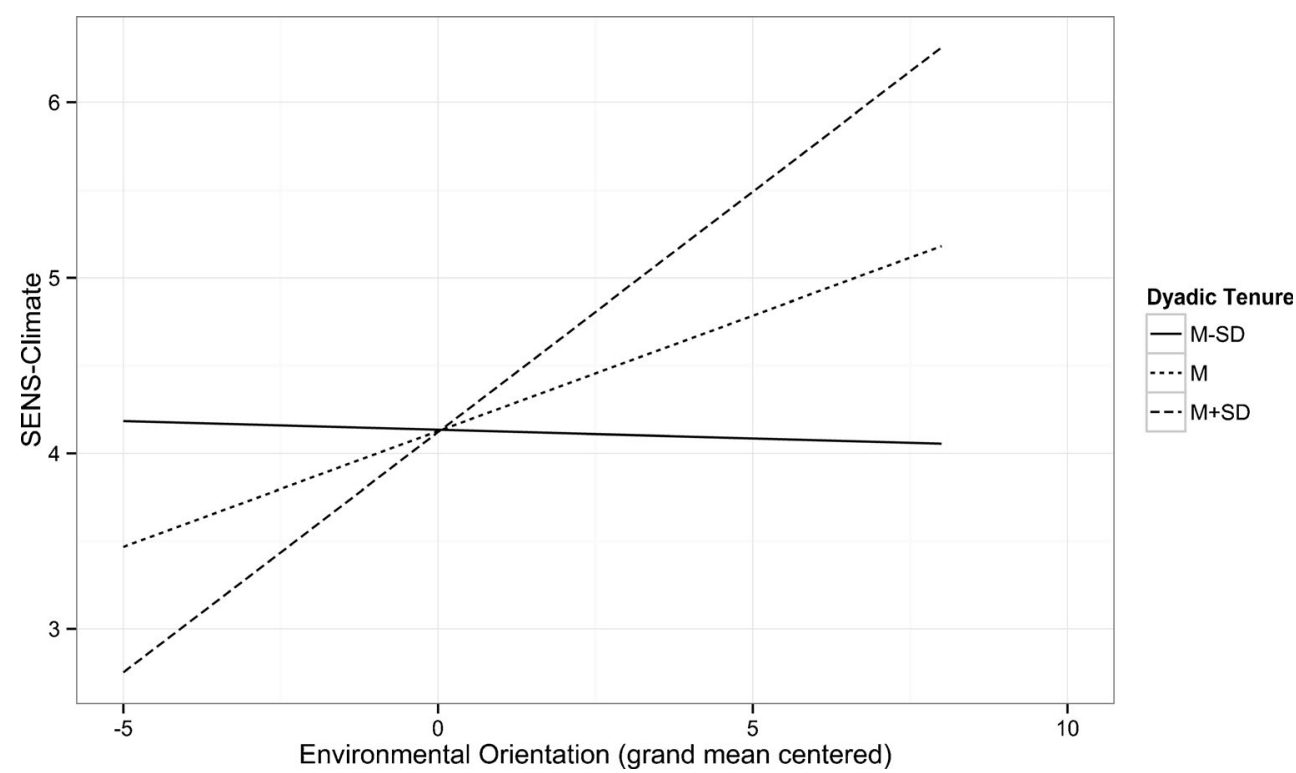


five interaction terms on the three dependent variables (green sales, regular sales, and margin). The results provide initial support for a mediating role of SENS-climate. When we included these antecedents and their interactions as controls, it did not significantly change the results, such that the positive direct effects of the SENS-climate on green sales $(\beta=.150$, $p<.05)$ and margin $(\beta=.139, p<.05)$ and its negative direct effect on regular sales $(\beta=-.194, p<.05)$ remained significant. The direct effects of pattern orientation, pattern variability, and transformational leadership on the three outcome variables turned out to be non-significant, except that pattern orientation had a significant, positive, direct effect on margins $(\beta=.270, p<.01)$

Finally, we directly tested for mediation with a Monte Carlo mediation approach to construct the confidence intervals for the indirect effects (Bauer et al. 2006; MacKinnon et al. 2004). Significant indirect effects emerge for pattern orientation and pattern variability, as well as a baseline effect of transformational leadership on all three dependent variables (see Table 3). Therefore, the SENS-climate mediated the antecedents' effects on the outcome variables in a way that indicated indirect-only mediation (Zhao et al. 2010). An exception is the mediating effect of the SENS-climate between pattern orientation and margin, which reveals complementary mediation, because pattern orientation also has a significantly positive direct effect on margins (Zhao et al. 2010). Overall, these results provide strong support for the mediating role of the SENS-climate.

\section{Discussion}

In the introduction, we emphasized that retailers can play a focal role in facilitating consumer adoption of green products,

Table 3 Results of Monte Carlo estimation of indirect effects

\begin{tabular}{llll}
\hline $\begin{array}{l}\text { Individual-level } \\
\text { impact }\end{array}$ & Green sales & Regular sales & Margin \\
\hline $\begin{array}{l}\text { Independent } \\
\text { variables }\end{array}$ & $\begin{array}{c}\text { (standardized } \\
\text { effect sizes) }\end{array}$ & $\begin{array}{c}\text { (standardized } \\
\text { effect sizes) }\end{array}$ & $\begin{array}{c}\text { (standardized } \\
\text { effect sizes) }\end{array}$ \\
$\begin{array}{l}\text { Independent variables (individual level): } \\
\text { Transformational } \\
\text { leadership }\end{array}$ & $.04^{*}$ & $-.05^{*}$ & $.04^{*}$ \\
$\begin{array}{l}\text { Independent variables (store level): } \\
\text { Pattern } \\
\text { orientation }\end{array}$ & $.10^{*}$ & $-.13^{*}$ & $.09^{*}$ \\
$\begin{array}{l}\text { Pattern } \\
\text { variability }\end{array}$ & $-.10^{*}$ & $.13^{* *}$ & $-.09^{*}$ \\
\hline
\end{tabular}

$N=182$. Confidence intervals are based on Monte Carlo simulations (cf., Preacher and Selig 2010). The standardizations of the indirect effects are based on Preacher and Hayes (2008)

$* p<.05 ; * * p<.01$ (two-tailed) though little research explores this role in depth (Gleim et al. 2013; Wu and Chen 2014). Our contribution is to develop and empirically assess a model that features SENS-climate as a central concept, offered as a mechanism through which retailers can stimulate sales associates to encourage consumers to buy green. The SENS-climate is based on a set of operational-level articulations that stimulate store-based, shared beliefs about environmentally responsible behaviors and serve the interests of the store, the company, and customers, in line with an environmental marketing doctrine. Through this process, retailers can address a key condition to facilitate consumer adoption of green products, namely, to gain credibility by implementing policies consistent with the sale of green products (Gleim et al. 2013).

To develop such consistency within stores, the patterns of managers' task-oriented actions are an important predictor of a SENS-climate. We find that store managers' pattern orientation is conducive to creating a work environment that supports environmentally responsible actions in sales associates' dayto-day operations. In support of this rationale, recent theory on stewardship posits that leaders function as role models, and their enacted stewardship convictions contribute to developing collectively held convictions among employees (Hernandez 2012). We also demonstrate that a store manager's pattern variability exerts a negative effect on SENS-climate perceptions, in line with contentions that the formation of shared norms at the work-unit level may be hindered by inconsistencies in situational cues (Weber et al. 2004). It also aligns with previous stewardship theory that indicates clarity and consistency in role expectations are paramount (Davis et al. 1997).

Beyond these main effects, we present evidence of a moderating role of dyadic tenure. Dyadic tenure strengthens the relationship between a manager's pattern orientation and employees' SENS-climate perceptions. It also boosts the positive influence of transformational leadership practices on SENSclimate perceptions. Apparently store managers' transformational leadership practices become more effective through continued investments over time. In line with Challagalla et al. (2014), we conceptualize these relational elements as methods to make the environmental marketing doctrine sustainable at an operational level. Recent claims similarly indicate that social exchange relationships support the development of a stewardship climate (Hernandez 2012). However, dyadic tenure did not affect the negative relationship between pattern variability and a SENS-climate. Longer relationships thus do not seem to act as remedies for a store manager's lack of consistency.

Of no less interest is our finding that transformational leadership, while demonstrating the expected baseline effect, did not moderate the impact of a store manager's pattern orientation and pattern variability on SENS-climate perceptions. This lack of moderation might arise because transformational 
leaders also strengthen employees' feelings of autonomy and self-efficacy, which decreases their dependence on the store manager as a role model (Menguc and Auh 2008). In addition, transformational leaders may be more aware of the importance of goals and how to communicate them (Berson and Avolio 2004), so they might exhibit less pattern variability because they realize it creates confusion, which would limit the potential for any moderating influence. We do note that the presence of a strong direct relationship between transformational leadership and SENS-climate perceptions suggests that a firm's environmental performance can be encouraged by open discussion and a "try as you go" approach to ideas and behaviors. Transformational leadership involves store managers going beyond policy and desired performance statements by actively engaging sales associates in strengthening the store's environmental responsibility. As many aspects of leadership can be learned or strengthened, our findings send a clear signal that retailers can improve the alignment between their overall performance and their environmental marketing doctrine.

At the sales associate-customer interface, our results contribute to a better understanding of the impact of SENSclimate perceptions on performance. Sales associates who perceive an enabling SENS-climate achieve more green but fewer regular sales. Thus, a SENS-climate appears to result in behavioral changes by sales associates at the customer interface, which in turn cause a shift in the kind of products sold. This finding contradicts previous research on environmental stewardship, which indicates no effects on total sales at the workunit level (de Ruyter et al. 2009). Moreover, our results imply that fostering a SENS-climate can enable sales associates to contribute to consumer adoption of eco-innovations, which reinforces the pivotal role of the retailer. There are options for firms to create shared value by integrating sustainability considerations in their organizational core, as suggested by Porter and Kramer (2006). Such evidence is well established for production firms, which can reduce waste-related costs by acting environmentally (King and Lenox 2002); it is encouraging to see that it also can work for retailers that integrate environmental responsibility at their frontline.

Finally, SENS-climate perceptions mediate the effects of store managers' task- and relationship-oriented actions on sales associates' performance outcomes. The only exception was the mediating effect of the SENS-climate between pattern orientation and margin, which indicated a complementary mediation. The direct effect of store managers' pattern orientation could stem from direct imitations of the store managers' role modeling behaviors. That is, rather than providing cues about what is appropriate, role modeling can be copied directly. If a store manager successfully sells green products with higher margins, she or he offers a prime example of how to achieve multiple goals at once. Thus, interventions at the store manager level can improve environmental performance at the individual sales associate level. Attitude change at the individual sales associate level, which requires substantially higher investments, is not the only available approach to foster environmental performance on the frontline. The message is a hopeful one: even though consumers seem reluctant to adopt green products, there is much that retailers can do internally to catalyze and accelerate this adoption, namely, by fostering a SENS-climate.

\section{Managerial implications}

Our findings have implications for marketing practice, especially for retailers, related to the enactment of principles on the shop floor. Establishing an explicit connection between operational experience and marketing doctrine seems particularly important for mid-size firms that tend to persist in a state of strategic flux. Such firms might lack the requisite resources to implement their strategic visions or establish their fit with daily operations on the frontline. For these firms, we identify a set of actionable guidelines that can reduce impulsivity and encourage considerations of the practical implications of strategic decisions.

First, we find that stronger SENS-climate perceptions result in higher achieved margins, so environmental performance does not necessarily come at a financial cost for the company. While retailers may initially be wary of promoting environmentally friendly products due to the expectation of lower margins and sales, the results of this study suggest that sales associates can achieve higher margins and sales of green products during their encounters with customers, and, therefore, alleviate managerial wariness.

Second, the central role of store managers in facilitating a SENS-climate means they are ideally placed to function as environmental champions. In this educational role, store managers should take responsibility for disseminating environmental practices among sales associates (Cronin et al. 2011). To assist them, environmental awareness programs tailored to store managers' specific needs could provide guidance on new environmental practices and raise awareness of how action patterns affect the SENS-climate. This approach should facilitate store managers' articulation of an environmental marketing doctrine. Moreover, our findings regarding the moderating role of sustainability suggest that stability in the manager base is conducive to the development of a SENS-climate. In sectors where it is routine to rotate managerial positions, retailers should find other ways to maintain this stability. It would require that pro-environmental practices are a fundamental part of the organization's overall strategy, to ensure consistency in messages and practices.

Third, training modules for store managers could build on a scenario- and script-based approach, similar to the ones we used (see the Web Appendix). Discussing behavioral scripts can help management trainees identify discrepancies between their behaviors and desired actions. A similar approach also 
could provide an audit of current management practices. Personal training programs then could focus on addressing any inconsistencies between the environmental marketing doctrine and the decisions made by (trainee) managers. Such educational approaches also might help transfer knowledge to channel partners or non-retail organizations that want to foster environmental responsibility in their organizations.

\section{Future research directions}

Recognizing a number of limitations to our study, we identify avenues for future research. We focused on the effects of leaders' action patterns on SENS-climate perceptions and controlled for individual-level factors (e.g., tenure, work status), but we did not specifically assess individual-level psychological mechanisms that might mediate or serve as an alternative explanation for the effects across the articulation antecedents, sustainability moderators, and climate perceptions. This limitation might have caused an upward bias in the effects we found. Therefore, further research should explore combinations of leadership actions and psychological-level mechanisms as antecedents of stewardship climates. It also would be interesting to examine the extent to which more specific aspects of leadership (e.g., underlying dimensions of transformational leadership) affect SENS-climate perceptions.

Store managers' pattern variability constitutes an important barrier to the development of a SENS-climate. We hope that further research identifies ways to reduce this pattern variability. For example, pre-posttest experimental designs could examine the impact of interventions (e.g., self-awareness training, role playing) designed to promote consistency and selfmonitoring in environmental orientation. In developing such study designs, researchers should note Hernandez's (2012) contention that individual or collective initiatives likely are more influential for shared stewardship beliefs than are topdown, prescriptive measures. Longitudinal research designs could track whether initiatives and changes in a store manager's pattern consistency remain sustainable over time.

Most stewardship research focuses on identifying antecedents. Our study shows that situational characteristics, such as dyadic tenure, can moderate the effectiveness of antecedents though. Additional research should focus more on potential moderators (e.g., incentive structures, consensus among employees, team composition) that might represent important boundary conditions for implementing a marketing doctrine for environmental responsibility on the shop floor. From a reverse perspective, further research might focus on tracing the influence of frontline attitudes and behaviors on shaping or refining environmental policies at the corporate level. This complementary perspective would be more reflective of the bidirectional nature of companies' adaptations to the challenges of establishing environmental responsibility as a strategic imperative.
Our results show that the creation of a SENS-climate does not necessarily invoke financial costs in the short term. Additional research should explore how promoting a SENSclimate affects financial performance in different contexts (e.g., changes in the economic situation, competitor strategies, supply considerations) and for companies that serve different customer segments (e.g., green versus resistant segments). It also would be interesting to investigate if the stimulation of a SENS-climate has different effects on performance at individual, team, and company levels and whether these effects change in the long run.

Linking to the wider cultural debate about attitudes toward the environment, the country in which this study took place is a horizontal, individualistic culture, such that its citizens tend to have positive attitudes toward the environment, which align closely with the attitudes dominant in horizontal collectivistic cultures. Countries characterized as vertical (whether individualistic or collectivistic) instead tend to reveal more negative environmental attitudes (Cho et al. 2013), possibly because vertical power orientations are linked to inward-looking views that create more perceived distance from the environment or the benefits of environmentally friendly actions. To advance this debate, researchers should establish cross-cultural differences in environmental stewardship, particularly those emphasized by Cho et al. (2013), in terms of the vertical-horizontal power dimension.

Finally, our study pertains to the retail context for household appliances. In considering the generalizability of our findings to other product categories, comparative studies would be of great relevance. Green issues are not considered consistently across product categories. However, there is agreement that the retailer is seen as playing a pivotal role across these categories in terms of informing the consumer. In particular they are seen as having a role of helping consumers to both understand the complexity of the environmental arguments and keep up to date with the latest innovations. Fast moving consumer goods buyers exhibit more mature consideration of green issues, compromising on price in favor of greener products, but purchases of small electrical appliances are dominated by brand considerations (McDonald et al. 2009). In the purchase of white goods, brand and price still dominate decisions but energy efficiency is emerging as an important third consideration. The adoption of green products may be inversely proportional to the perceived risks (including potential inconvenience), such that the underpinning technology might explain the slow adoption of Hybrid Electric Vehicles (Lamberson 2008). Yet the role of the retailer is uniform: it informs and helps consumers at the point of sale, especially by making green products relevant to their everyday life. Further research should seek to define how retailers might best explicate the complex green options available to consumers, while also accounting for maturation of the green marketplace and reducing perceived risks. 


\section{Appendix}

Table 4 Measures and measurement criteria

\begin{tabular}{|c|c|c|}
\hline Measures & Standard loadings & $\mathrm{t}$-value ${ }^{\mathrm{a}}$ \\
\hline \multicolumn{3}{|l|}{ SENS-climate $[n=3, \mathrm{CR}=.921, \mathrm{AVE}=.797]$} \\
\hline For own actions & $.97^{b}$ & N.A. \\
\hline 1. The sales associates in our store display a collective sense of responsibility for the environment. & .75 & N.A. \\
\hline 2. Sales associates in our store feel accountable for the environmental impact of our work. & .83 & 11.76 \\
\hline 3. In our store, we feel that we have to act in service of the environment when trying to achieve our sales goals. & .69 & 9.64 \\
\hline 4. Sales associates in our store seek to balance long-term environmental goals and short-term profitability goals. & .66 & 9.22 \\
\hline 5. Sales associates working in our store are willing to make sacrifices for the good of the environment. & .73 & 10.32 \\
\hline \multicolumn{3}{|l|}{ For company initiatives } \\
\hline 6. We come up with initiatives to make our company more environmentally friendly. & $.95^{b}$ & 9.07 \\
\hline 7. We believe that we need to play a leading role to make our company more sustainable. & .79 & N.A. \\
\hline 8. If we have an idea that can help our company to improve its environmental performance, & .69 & 9.86 \\
\hline we take the initiative to execute it. & .72 & 10.35 \\
\hline For customers' choices & $.74^{b}$ & 7.74 \\
\hline 9. In addressing customer demands, we attempt to come up with solutions that are best for the environment. & .77 & N.A. \\
\hline 10. We encourage customers to seek a balance between personal and environmental interests. & .84 & 11.12 \\
\hline 11. We educate customers about the environmental impact of the products in our assortment. & .72 & 9.76 \\
\hline \multicolumn{3}{|l|}{ Transformational Leadership ${ }^{c}[n=4, \mathrm{CR}=.954, \mathrm{AVE}=.837]$} \\
\hline Idealized influence & $.95^{b}$ & N.A. \\
\hline 1. IIA1 & .60 & N.A. \\
\hline 2. IIA2 & .63 & 7.50 \\
\hline 3. IIA3 & .68 & 7.91 \\
\hline 4. IIB1 & .68 & 7.94 \\
\hline 5. IIB2 & .62 & 7.43 \\
\hline 6. IIB3 & .67 & 7.90 \\
\hline Inspirational motivation & $.91^{b}$ & 7.32 \\
\hline 7. IM1 & .74 & N.A. \\
\hline 8. IM2 & .72 & 9.41 \\
\hline 9. IM3 & .77 & 9.99 \\
\hline Intellectual stimulation & $.93^{b}$ & 6.54 \\
\hline 10. IS1 & .60 & N.A. \\
\hline 11. IS2 & .71 & 8.04 \\
\hline 12. IS3 & .74 & 8.27 \\
\hline Individual consideration & $.88^{b}$ & 7.09 \\
\hline 13. IC1 & .72 & N.A. \\
\hline 14. IC2 & .56 & 7.13 \\
\hline 15. IC3 & .82 & 9.99 \\
\hline
\end{tabular}

CR composite reliability, $A V E$ average variance extracted, $N . A$. not applicable

${ }^{\text {a }}$ All t-values are $p<.05$

${ }^{\mathrm{b}}$ These refer to the standardized loadings of the first-order constructs on the higher-order construct

${ }^{\mathrm{c}}$ Because of copyright restrictions, we cannot provide the item wording of the transformational leadership scale here 
Open Access This article is distributed under the terms of the Creative Commons Attribution 4.0 International License (http:// creativecommons.org/licenses/by/4.0/), which permits unrestricted use, distribution, and reproduction in any medium, provided you give appropriate credit to the original author(s) and the source, provide a link to the Creative Commons license, and indicate if changes were made.

\section{References}

Aiken, L. S., \& West, S. G. (1991). Multiple regression: Testing and interpreting interactions. Thousand Oaks: Sage.

Anderson, J. C., \& Gerbing, D. W. (1988). Structural equation modeling in practice: a review and recommended Two-step approach. Psychological Bulletin, 103, 411-423.

Andrews, T. L., \& Rogelberg, S. G. (2001). A new look at service climate: its relationship with owner service values in small businesses. Journal of Business and Psychology, 16, $119-132$.

Bass, B. M. (1999). Two decades of research and development in transformational leadership. European Journal of Work and Organizational Psychology, 8, 9-32.

Bauer, D. J., Preacher, K. J., \& Gil, K. M. (2006). Conceptualizing and testing random indirect effects and moderated mediation in multilevel models: New procedures and recommendations. Psychological Methods, 11, 142-163.

Berson, Y., \& Avolio, B. J. (2004). Transformational leadership and the dissemination of organizational goals: a case study of a telecommunication firm. Leadership Quarterly, 15, 625-646.

Best Buy Co. Inc. (2010). People, Technology and Power in the Connected World: Annual Sustainability Report Fiscal 2010. Retrieved June 12, 2014 from http://www.socialfunds.com/shared/ reports/1279598903_BestBuy_2010_Sustainability_Report.pdf

Bishop, M. M., \& Barber, N. A. (2015). Should I Pay more? the relationship between normative beliefs and willingness-to-Pay for organic and local products. Journal of Marketing Theory and Practice, 23, 94-106.

Block, P. (1993). Stewardship: Choosing service over self-interest. San Francisco: Berrett-Koehler.

Brady, K., Hendry, J., \& Kanchwala, S. (2010). Retail: A Sustainability Benchmark. Retrieved June 12, 2014 from http://www.greenbiz. com/business/research/report/2010/04/23/retail-sustainabilitybenchmark

Caldwell, C., Hayes, L., Bernal, P., \& Karri, R. (2008). Ethical stewardship - implications for leadership and trust. Journal of Business Ethics, 78, 153-164.

Casimir, G. (2001). Combinative aspects of leadership style: the ordering and temporal spacing of leadership behaviors. Leadership Quarterly, 12, 245-278.

Castle, S. (2011). Survey: Americans Open to Efficiency Technologies, but Awareness is Key. Retrieved Oct 31, 2014 from http://greentechadvocates.com/2011/05/26/surveyamericans-open-to-efficiency-technologies-but-awareness-iskey/

Challagalla, G., Murtha, B. R., \& Jaworski, B. (2014). Marketing doctrine: a principles- based approach to guiding marketing decision making in firms. Journal of Marketing, 78, 4-20.

Cho, Y.-N., Thyroff, A., Rapert, M. I., Park, S.-Y., \& Lee, H. J. (2013). To be or not to be green: exploring individualism and collectivism as antecedents of environmental behavior. Journal of Business Research, 66, 1052-1059.
Cronin, J., Smith, J., Gleim, M., Ramirez, E., \& Martinez, J. (2011). Green marketing strategies: an examination of stakeholders and the opportunities they present. Journal of the Academy of Marketing Science, 39, 158-174.

Davis, J. H., Schoorman, F. D., \& Donaldson, L. (1997). Toward a stewardship theory of management. Academy of Management Review, $22,20-47$.

de Ruyter, K., de Jong, A., \& Wetzels, M. G. M. (2009). Antecedents and consequences of environmental stewardship in boundary-spanning B2B teams. Journal of the Academy of Marketing Science, 37, 470 487.

Deutsch Salamon, S., \& Robinson, S. L. (2008). Trust that binds: the impact of collective felt trust on organizational performance. Journal of Applied Psychology, 93, 593-601.

Donaldson, L., \& Davis, J. H. (1991). Stewardship theory or agency theory: CEO governance and shareholder returns. Australian Journal of Management, 16, 49-65.

Ehrhart, M. G., Schneider, B., \& Macey, W. H. (2013). Organizational climate and culture: An introduction to theory, research, and practice. New York: Routledge.

Electrolux. (2013). We want clean, green appliances, Electrolux consumers say. Retrieved Oct 31, 2014 from http://group.electrolux. com/en/we-want-clean-green-appliances-electrolux-consumers-say$17755 /$

Euromonitor International. (2010a). The Future's Electric: Prospects for Electronics and Appliance Specialist Retailers - World. Retrieved June 12, 2014 from http://www.euromonitor.com/the-futureselectric-prospects-for-electronics-and-appliance-specialist-retailersworld/report

Euromonitor International. (2010b). Global Discretionary Goods \& Services Markets in 2009 and 2010: Legacy of the Downturn (Part 2). Retrieved June, 2014 from http://www.euromonitor.com/ global-discretionary-goods-and-services-markets-in-2009-and2010-legacy-of-the-downturn-part-2/report

Fornell, C., \& Larcker, D. F. (1981). Evaluating structural equation models with unobservable variables and measurement error. Journal of Marketing Research, 18, 39-50.

Girod, B., van Vuuren, D. P., \& Hertwich, E. G. (2014). Climate policy through changing consumption choices: Options and obstacles for reducing greenhouse gas emissions. Global Environmental Change, $25,5-15$.

Gleim, M. R., Smith, J. S., Andrews, D., \& Cronin, J. J., Jr. (2013). Against the green: a multi-method examination of the barriers to green consumption. Journal of Retailing, 89, 44-61.

Goldstein, N. J., Cialdini, R. B., \& Griskevicius, V. (2008). A room with a viewpoint: using social norms to motivate environmental conservation in hotels. Journal of Consumer Research, 35, 472-482.

Griskevicius, V., Tybur, J. M., \& van den Bergh, B. (2010). Going green to Be seen: status, reputation, and conspicuous conservation. Journal of Personality and Social Psychology, 98, 392-404.

Gunningham, N. (2009). Shaping corporate environmental performance: a review. Environmental Policy \& Governance, 19, 215-231.

Hernandez, M. (2008). Promoting stewardship behavior in organizations: a leadership model. Journal of Business Ethics, 80, 121-128.

Hernandez, M. (2012). Toward an understanding of the psychology of stewardship. Academy of Management Review, 37, 172-193.

Hofstra, N., \& Huisingh, D. (2014). Eco-innovations characterized: a taxonomic classification of relationships between humans and nature. Journal of Cleaner Production, 66, 459-468.

Homburg, C., Wieseke, J., \& Bornemann, T. (2009). Implementing the marketing concept at the employee-customer interface: the role of customer need knowledge. Journal of Marketing, 73, 64-81.

Hox, J. J. (2002). Multilevel analysis: Techniques and applications. Mahwah, NJ: Lawrence Erlbaum Associates, Inc.

Jöreskog, K. G., \& Sörbom, D. (2006). LISREL 8.80 for windows. Lincolnwood: Scientific Software International, Inc. 
Karakaya, E., Hidalgo, A., \& Nuur, C. (2014). Diffusion of eco-innovations: a review. Renewable and Sustainable Energy Reviews, 33, 392-399.

King, A., \& Lenox, M. (2002). Exploring the locus of profitable pollution reduction. Management Science, 48, 289-299.

Kotler, P. (2011). Reinventing marketing to manage the environmental imperative. Journal of Marketing, 75, 132-135.

Lai, K., Cheng, T. C. E., \& Tang, A. K. Y. (2010). Green retailing: factors for success. California Management Review, 52, 6-31.

Lamberson, P. (2008). The diffusion of hybrid electric vehicles. Future Research Directions in Sustainable Mobility and Accessibility. Retrieved from http://www.umsmart.org/project_research/Future directions.pdf.

Langan, R. (2014). Research at the intersection of marketing and CSR. In R. P. Hill \& R. Langan (Eds.), Handbook of research on marketing and corporate social responsibility (pp. 3-41). Northampton: Edward Elgar Publishing Inc.

Lee, K.-H., Cin, B. C., \& Lee, E. Y. (2014). Environmental Responsibility and Firm Performance: The Application of an Environmental, Social and Governance Model. Business Strategy and the Environment.

Leonidou, C. N., Katsikeas, C. S., \& Morgan, N. A. (2013). "Greening" the marketing mix: do firms do it and does it pay off? Journal of the Academy of Marketing Science, 41, 151-170.

MacKinnon, D. P., Lockwood, C. M., \& Williams, J. (2004). Confidence limits for the indirect effect. Multivariate Behavioral Research, 39, 99-128.

March, J. G. (1994). A primer on decision making: How decisions happen. New York: The Free Press.

McDonald, S., Oates, C., Thyne, M., Alevizou, P., \& McMorland, L.-A. (2009). Comparing sustainable consumption patterns across product sectors. International Journal of Consumer Studies, 33, 137-145.

Menguc, B., \& Auh, S. (2008). Conflict, leadership, and market orientation. International Journal of Research in Marketing, 25, 34- 45.

Mills, B., \& Schleich, J. (2010). What's driving energy efficient appliance label awareness and purchase propensity? Energy Policy, 38, 814 825.

Morhart, F. M., Herzog, W., \& Tomczak, T. (2009). Brand-specific leadership: turning employees into brand champions. Journal of Marketing, 73, 122-142.

Nejad, M. G., Sherrell, D. L., \& Babakus, E. (2014). Influentials and influence mechanisms in New product diffusion: an integrative review. Journal of Marketing Theory \& Practice, 22, 185-208.

Nipkow, J., Josephy, B., Bush, E., \& Michel, A. (2012). Cold appliances: recommendations for policy design. Retrieved February 2, 2014 from http://www.topten.eu/uploads/File/Recommendations_Cold_ May\%202012.pdf

OECD. (2008). Promoting sustainable consumption: Good practices in oecd countries. Paris: OECD Publishing.

Olson, E. L. (2013). It's not easy being green: the effects of attribute tradeoffs on green product preference and choice. Journal of the Academy of Marketing Science, 41, 171-184.

Ottman, J. A., Stafford, E. R., \& Hartman, C. L. (2006). Avoiding green marketing myopia: ways to improve consumer appeal for environmentally preferable products. Environment: Science and Policy for Sustainable Development, 48, 22-36.

Podsakoff, P. M., Mackenzie, S. B., Lee, J.-Y., \& Podsakoff, N. P. (2003). Common method biases in behavioral research: a critical review of the literature and recommended remedies. Journal of Applied Psychology, 88, 879-903.

Porter, M. E., \& Kramer, M. R. (2006). Strategy \& society: the link between competitive advantage and corporate social responsibility. Harvard Business Review, 84, 78-92.
Preacher, K. J., \& Hayes, A. F. (2008). Contemporary approaches to assessing mediation in communication research. In A. F. Hayes, M. D. Slater, \& L. B. Snyder (Eds.), The sage sourcebook of advanced data analysis methods for communication research (pp. 13 54). Thousand Oaks: Sage.

Preacher, K. J., \& Selig, J. P. (2010). Monte Carlo Method for Assessing Multilevel Mediation: An Interactive Tool for Creating Confidence Intervals for Indirect Effects in 1-1-1 Multilevel Models. Retrieved June 1, 2014 from http://www.quantpsy.org/medmc/medmc111.htm

Prindle, W. R. (2010). From Shop Floor to Top Floor: Best Business Practices in Energy Efficiency. Retrieved June 12, 2014 from http://www.c2es.org/docUploads/PEW_EnergyEfficiency_ FullReport.pdf

Rasbash, J., Browne, W., Healy, M., Cameron, B., \& Charlton, C. (2010). MLwiN 2.22. Bristol, UK: University of Bristol, Centre for Multilevel Modelling.

Raudenbush, S. W., \& Bryk, A. S. (2002). Hierarchical linear models: Applications and data analysis methods (Vol. 1). Thousand Oaks: Sage.

Schneider, B., Bowen, D. E., Ehrhart, M. G., \& Holcombe, K. M. (2000). The climate for service: Evolution of a construct. In N. M. Ashkanasy, C. P. M. Wilderom, \& M. F. Peterson (Eds.), Handbook of organizational culture and climate (pp. 21-36). Thousand Oaks: Sage Publications, Inc.

Shimp, T. A., Hyatt, E. M., \& Snyder, D. J. (1991). A critical appraisal of demand artifacts in consumer research. Journal of Consumer Research, 18, 273-283.

Tenbrunsel, A. E., \& Messick, D. M. (1999). Sanctioning systems, decision frames, and cooperation. Administrative Science Quarterly, 44, 684-707.

Thongplew, N., Spaargaren, G., \& Van Koppen, C. S. A. (2014). Greening consumption at the retail outlet: the case of the Thai appliance industry. International Journal of Sustainable Development \& World Ecology, 21, 99-110.

Walumbwa, F. O., Avolio, B. J., \& Zhu, W. (2008). How transformational leadership weaves its influence on individual Job performance: the role of identification and efficacy beliefs. Personnel Psychology, 61, $793-825$.

Weber, J. M., Kopelman, S., \& Messick, D. M. (2004). A conceptual review of decision making in social dilemmas: applying a logic of appropriateness. Personality and Social Psychology Review, 8, 281307.

Wieseke, J., Ahearne, M., Lam, S. K., \& Dick, R. (2009). The Role of Leaders in Internal Marketing. Journal of Marketing, 73, 123-145.

Wofford, J. C., \& Goodwin, V. L. (1990). Effects of feedback on cognitive processing and choice of decision style. Journal of Applied Psychology, 75, 603-612.

Wu, S.-I., \& Chen, Y.-J. (2014). The impact of green marketing and perceived innovation on purchase intention for green products. International Journal of Marketing Studies, 6, 81-100.

WWF. (2014). Reduce your impact. Retrieved September 7, 2014 from http://wwf.panda.org/how you can help/live green/

Yaffe, T., \& Kark, R. (2011). Leading by example: the case of leader OCB. Journal of Applied Psychology, 96, 806-826.

Zhao, X., Lynch, J. G., Jr., \& Chen, Q. (2010). Reconsidering baron and Kenny: myths and truths about mediation analysis. Journal of Consumer Research, 37, 197-206.

Zohar, D., \& Luria, G. (2004). Climate as a social-cognitive construction of supervisory safety practices: scripts as proxy of behavior patterns. Journal of Applied Psychology, 89, 322-333.

Zohar, D., \& Tenne-Gazit, O. (2008). Transformational leadership and group interaction as climate antecedents: a social network analysis. Journal of Applied Psychology, 93, 744-757. 